\title{
Microbiology Specimen Elapsed Time
}

National Cancer Institute

\section{Source}

National Cancer Institute. Microbiology Specimen Elapsed Time. NCI Thesaurus. Code C87905.

The interval between two microbiology specimen reference time points. 